\title{
A Cognitive and Emotional Self: A Dynamic Relationship between a Dual Self Embedded in the Autonomic Nervous System
}

\author{
Ravinder Jerath*, Connor Beveridge \\ Charitable Medical Healthcare Foundation, Augusta, GA, USA \\ Email: ^Rj605r@aol.com, beveridge.connor00@gmail.com
}

How to cite this paper: Jerath, R., \& Beveridge, C. (2020). A Cognitive and Emotional Self: A Dynamic Relationship between a Dual Self Embedded in the Autonomic Nervous System. Psychology, $11,1108-1124$.

https://doi.org/10.4236/psych.2020.118073

Received: July 11, 2020

Accepted: August 16, 2020

Published: August 19, 2020

Copyright ( 2020 by author(s) and Scientific Research Publishing Inc. This work is licensed under the Creative Commons Attribution International License (CC BY 4.0).

http://creativecommons.org/licenses/by/4.0/ (c) (i) Open Access

\begin{abstract}
The true nature of self has been considered one of the greatest mysteries since philosophical thought first arose. We assert that states of mind relating to the self are greatly influenced if not underlain by the autonomic nervous system. A duality of the self is an ancient concept that has been described by philosophers around the globe, but has not been explained scientifically. We propose a duality to the self which can be associated physiologically with the duality of the autonomic nervous system. In the sympathetic dominant state we often perceive our relationship to people and the environment in an emotional manner, with the parasympathetic dominant state more associated with more cognitive states of mind. We illustrate that our thought processes and moods are heavily influenced by a relationship and levels of dominance between our embodied, egotistical emotional self and a cognitive self that has more blurred boundaries between "self and other". The model of a dual self we propose elucidates more reasonable understanding of self-talk and self-perception. Preeminent and founding fathers of psychology such as William James and Sigmund Freud have proposed a multi-part self, however lacked empirical work to support their hypotheses. We have however reviewed significant scientific works to support our concept of self. We suggest that through understanding this dual nature and the nature of the self in general, one may exert more control over moods and thought patterns, therefore improving mental health as mental atmosphere.
\end{abstract}

\section{Keywords}

Self, Consciousness, Emotional Self, Cognitive Self, Autonomic Nervous System, Self-Talk, Self-Perception 


\section{Introduction}

"To access your subconscious, is to access your 'higher-self."

-Kevin Michel

Often more so than conversations with others (Heavey \& Hurlburt, 2008), people hold conscious and subconscious conversations with themselves in order to guide, plan, and monitor internal activity, especially when trying to achieve goals, leading to increased performance in a variety of tasks (Hatzigeorgiadis \& Galanis, 2017; Geurts, 2018). How can one person hold so much inner chatter? In order to provide insight into this and other observations on the self, we propose a dualistic, polar nature of the self and cite physiological and psychological research to support this duality. A dualistic view of the self has been described in ancient literature, philosophy, and religion (Blavatsky, 1889; Holcombe \& Holcombe, 2005). Modern neuroscience has now made it possible to support scientifically the theory on a neural basis of self.

In our hypothesis on the dual nature of the self, we point to a relationship between a cognitive and a primary emotional self which draws similarities to Sigmund Freud's and William James' multipart self. We indicate a "higher" state of consciousness as a state in which the impulsive emotional mind is constrained and the humble cognitive self expands into awareness and dominance. In the "lower" state, one exists in a more primal state of mind which is evolutionary purposed for immediate, selfish survival. Unconscious activity is the dominant force in the mind and estimates by many neuropsychologists, such as Frith, reveal 90\% - 99\% of brain activity is unconscious (Praet, 2012). Eagleman describes the conscious mind as "a stowaway on a transatlantic steam ship, taking credit for the journey without acknowledging the massive engineering underfoot" (Eagleman, 2011).

The integrated information theory of consciousness quantifies experience and asserts certain experiences have greater amounts of consciousness than others (Oizumi et al., 2014). When one enters the higher state of mind, we suggest they actually become quantitatively more conscious as the subconscious mind gradually comes into awareness. While these two selves remain differentiated in this state, the constraints of the emotional mind are loosened and one is free to observe rather than act impulsively. A common metaphor for this hidden mind is an iceberg, with conscious brain activity in our view as the tip of the iceberg, while a massive chunk of our minds hidden from our own awareness as the remaining ice hidden below the water. When one approaches a higher state of mind, the ice hidden below the water may be revealed.

With this article, we hope to provide a window into the self, mapping the mind and inspiring future research by providing scientific support for the ancient concept of a dual self.

\section{Prevailing Views of the Self}

A modern, prevailing view on the self is that it consists of two components: a 
phenomenal self-representation consisting of our bodies and behavior, the minimal self, and a narrative self which consists of our social and autobiographical self-perceptions (Tsakiris et al., 2007). Studies show the minimal self is plastic and the boundaries between self and other can be modified so that aspects of another person, agent, or object can be attributed as a part of one's own self so long as there is synchrony between one's intentions and the other's actions (Hommel, 2009). William James produced some of the first empirical understandings of the self in psychology, creating a distinction between the executive self as the knower/experiencer (" $\mathrm{I}$ "), and the self as the object to be known/experienced ("me") (James, 1890). James was the first to propose this idea of self as a "double", made of two poles. He proposed one pole consists of inner events while the other consists of awareness of those events, thus the "I"/"me" distinction. Freud described the self in a similar manner but proposing three distinct self agents which interact to form the whole psyche. Freud's version of a lower self is the "id", responsible for impulsive, instinctual desires. His version of the higher self is the "super-ego", a humble, contemplative, moralizing agent. Included in this model is the "ego", which he said mediates between the super-ego and id.

Current empirical evidence suggests the hidden unconscious mind can contain thought processes, interests, motivations, memories, repressed feelings, automatic skills, habits, subliminal perceptions, automatic reactions, and so on (Westen, 1999). This unconscious mind is the "me" of James' duality of self. This duplex self has been explored by other authors such as Gerald Edelman. Edelman has identified a higher order consciousness that arises from a primal, primary consciousness which is not aware of itself (Edelman, 2003). The higher order consciousness allows for self-awareness and introspection, leading to consciousness of being conscious (Edelman, 2003). In our model of self, we will describe a "lower" emotional self, which although a simplification, can correspond to Edelman's primary consciousness, and James' "I", and a "higher" cognitive self which can correspond Edelman's higher order consciousness and James' "me".

Current views posit that the self plays a significant role in motivation, cognition, and social identity (Sedikides \& Spencer, 2007). A promising account on the evolutionary origins of human self-hood arises at the interface between biological processes of the body and the sociocultural and ecological network to which that person belongs (Baumeister \& Bushman, 2010). Self-awareness of how we are thinking, feeling, and behaving allows us to be good group members and judge ourselves against group norms (Heatherton, 2010). Self-awareness lets us identify ourselves as distinct from others and think critically about what makes us unique, without which the social world as we know it would not function (Heatherton, 2010). Too much self-directed thinking can be maladaptive however and is associated with depression and negative thought patterns (Leary, 2004; Donaldson et al., 2007).

The Self has traditionally been exclusive to the field of philosophy, by modern 
techniques and concepts in cognitive neuroscience have allowed the analysis of the self through more empirical methods (Musholt, 2013). Through analysis of brain activity, the default mode network (DMN) has become the most probable neural correlate for the normal experience of self, creating a coherent framework for such a sense (Fingelkurts et al., 2016). The modules of the DMN (middle frontal gyri, frontal medial areas, middle temporal gyri, occipital gyri, and precunei) seem to be most active and synchronized when people perform self-related tasks, have self-generated thoughts, and experience mind-wandering (Fingelkurts et al., 2011; Andrews-Hanna et al., 2014). The strongest empirically supported module of the DMN as a neural correlate of self-related processing is the medial prefrontal cortex (Moran et al., 2013), associated with self-referential memory (Macrae et al., 2004), self-reflection (Farb et al., 2007), self-awareness (Eisenberger et al., 2005), and self-relevance (Moran et al., 2006).

The physical sense of self has been proposed to be embedded in an internal, virtual, 3D coordinate matrix of which all perception must be embedded for it to be experienced (Revonsuo, 2006; Fingelkurts et al., 2010; Jerath et al., 2015). The center of this $3 \mathrm{D}$ coordinate matrix is the where the mental self is experienced to be localized (Revonsuo, 2006). Such a physical representation of the self has been associated with a part of the parietal lobe, a posterior component of the DMN (Fingelkurts et al., 2016). The orientation association area of the parietal lobe creates a 3D sense of self by defining a boundary between self and non-self, thus orienting us with our environment. Our sense of self can thus be viewed as a manifestation of our interaction with the outside world (Nataraja, 2008). During transcendental experiences, there has been demonstrated a dramatic decrease in activity of this area, coinciding with dissolving of the sense of time and space as well as the physical boundary between the self and other (Newberg \& D'aquili, 1999).

Self-talk has been shown to increases one's ability to control thoughts, feelings, and behavior during stress (Moser et al., 2017), and has been associated with a variety of mental functions including planning, reasoning, motivation, and problem solving (Kales et al., 1976; Vicente \& Martinez Manrique, 2011). Self-talk is internal chatter, verbal and non-verbal, that combines conscious thoughts with our unconscious nature (Hardy, 2006), and is an essential part of human psychology which comes naturally to us (Geurts, 2018) as well as to other species (Jensvold, 2014). This can include internal dialogue, thoughts, facial expressions, and motor activity (Theodorakis et al., 2001). Plato first identified self-talk in $369 \mathrm{BC}$ as a conversation one has with oneself most evident in common thinking (Jowett, 1871). Self-talk appears more when performing more difficult tasks (Fernyhough \& Fradley, 2005), and it has been proposed in part to provide a means of commitments to oneself that allow for the coordination and constrainment of actions (Geurts, 2018).

The default space theory and other consciousness theories explain how the external 3D space and environment defaults into an internal 3D mind-body space in which it is consciously experienced (Jerath et al., 2015). From this pers- 
pective, we are aware of the external space, however, this experience we deem external is really occurring via an internal reflection of the external. Through meditation, predisposition, or other avenues, we may become aware of this "live" space within us (Jerath et al., 2016). This feeling of a world within our minds may generate abnormal psychological states if a person misidentifies this internal space as a self-developed/self-controlled reality or as if it were a virtual reality. We propose narcissism, grandiose delusions, and other personality disorders may originate internally by this mechanism.

The internal world our minds create in reflection of the external world is basically a virtual reality; however, this virtual reality is a simulation of the external world, not something drawn purely from imagination (Jerath \& Beveridge, 2019). Due to our consciousness being such a virtual reality, some may identify it as such in maladaptive ways. The conscious reality we experience can be considered an "informed hallucination" or representation of the world (Fingelkurts et al., 2010). Although we experience it as true reality, our experience of self is also part of this representation (Fingelkurts et al., 2010). What we experience is heavily influenced by top-down predications and this also applies to the self. An illusion that can be performed at home demonstrates this top-down dominance of self-perception. The "rubber-hand illusion" shows that our sense of bodily self can be easily modified by mental expectations. In this illusion, focusing one's attention on an artificial hand being stroked in a synchronous manner with one's concealed hand results the participant experiencing the artificial hand as truly being their real hand (Botvinick \& Cohen, 1998). Similar experiments using virtual reality lead participants to experience virtual body parts as their own (Ma et al., 2017). Thus, top-down influences can easily overturn bottom-up signaling.

\section{The Autonomic Nervous System}

We describe in our hypothesis that interplays between the cognitive and emotional selves are correlated with varying tones of the autonomic nervous system. The broad spectrum of sympathetic and parasympathetic extremes of the autonomic nervous system and their coexistence at various levels of dominance is fundamental to human physiology. Various feelings, moods and emotions are accompanied by their own specific and non-specific physiological reflection in the ANS (Kreibig, 2010). We have previously explored how the state of our ANS is readily modulated through breathing rate, pattern, depth, and voluntary thought processes (as in the breathing technique, pranayama) (Jerath et al., 2006). The two states of the ANS coexist at any given time; however the dominance by either one influences the internal mental atmosphere (Levenson, 2014). Altruistic mind-set greatly benefits social mammals such as ourselves as we are much more likely to survive as in a cohesive group than alone (de Waal, 2007). Of course, there are times in a mammal's day when it needs to abandon this altruistic mind-set in order to keep itself alive. This is the nature of the "fight-or-flight" response of the sympathetic nervous system (Brodal, 2004). When the danger 
has passed, the mammal can relax, socialize, and put more effort toward compassionate goals, which benefit its pack. This is when the parasympathetic system becomes dominate.

Modern times have brought us into a unique circumstance in relation to the ANS. In prehistoric and even pre-modern times, our sympathetic nervous systems were only dominant when we came into contact with a predator or fought with other groups (Nesse et al., 2016). In modern times however, we find ourselves in constant states of stress due to our jobs and our tendencies to commit ourselves to goals and responsibilities we cannot achieve. These outdated survival mechanisms have lead us into a state of "sympathoneural hypertonicity" in which our sympathetic nervous system stays in overdrive. This condition may be in many physiological and psychological impairments (Dequattro and Hamad, 1985). Moderate activation of the sympathetic nervous system can have a positive psychological role as when we experience eustress which gives one a resultant feeling of fulfillment (Nelson and Simmons, 2004). However, in modern times, we seem to be stuck in a state of distress which over activates the sympathetic system. We assert that through techniques such as pranayama, one can restore the ANS balance and improve self-relationship by reducing distress, driving us to a more cognitive-dominated self relationship.

Studies show how chronic imbalance of the ANS with over activation of the sympathetic system is a potent risk factor for adverse health including death from cardiovascular ailments (Curtis and O'Keefe, 2002). Interventions such as exercise have been shown to improve health outcomes by increasing parasympathetic activity and attenuating sympathetic hyperactivity (Curtis \& O'Keefe, 2002). A main feature of cardiovascular disease is increased sympathetic activity and this increase is also associated with increased mortality (Malpas, 2010). Although sympathetic nerves are always somewhat active, providing continuous constriction of blood vessels, overactivity can lead to excessive vasoconstriction (Malpas, 2010). The sympathetic system is also involved in a variety of other physiological process such as metabolism and renal control, and many disease states of these processes are also associated with chronically elevated sympathetic activity (Fisher et al., 2009). Conditions that are associated with this overactivity include diabetes (Huggett Robert et al., 2003), obesity (Grassi et al., 2007), pre-eclampsia (Greenwood et al., 2003), depression (Barton et al., 2007), kidney disease (Converse et al., 1992), and others.

\section{Hypothesis}

We view ourselves as a spatially finite person with a body and feelings. We acknowledge as part of ourselves our looks, age, gender, and other physical attributes as well as the various shades of emotions such as fear, anger, love, and hate. This reflection of our own selves into a singular being is generally more active consciously and drives our behavior in various cultural and inter-personal roles. We propose, as the "Father of American psychology" William James did, a duality of the self (James, 1890), which is also similar to Freud's tri-part self of 
the ego, super-ego, and id. Similar to James' "I" and Freud's id, we propose a less conscious, emotional self, and similar to James' "me" and Freud's super-ego, an often, in modern times, suppressed cognitive self. The emotions apart of this emotional self include primordial emotions which are the primal, homeostatic, instinctual feelings which drive one to satisfy biological needs. These include hunger, thirst, sexual drives, aggression, and drives to acquire pleasure and avoid pain (Denton, 2006). Thus, our hypothesis is that there exist two distinct selves which emerge from certain brain networks and that these two selves interact in an intimate relationship to produce the singular sense of self we all experience. These two selves exist in varying levels of dominance reflected by the autonomic nervous system.

Dynamic interactions between these two selves lead to the unified phenomenal and psychological construct of self as we naturally understand it. Although our hypothesis is compatible with prevailing views on the self, it differs from these prevailing views in that we propose a spectrum of self beyond the minimal self and narrative selves and extend it to neurology. We propose that a unified experience of self and consciousness and a unified nature of behavior exist due to a spectrum of dominance and interaction between the cognitive and emotional selves.

Although the emotional self is strongly associated with conscious experience and the higher with unconscious being, these selves are not identical to the conscious and unconscious. The emotional self exists solely in the "now", or "remembered present" as described by Gerald Edelman (Demiralp et al., 2006), acting on impulse and basic survival drives. Thus, this self is similar to Edelman's "primary consciousness" in that is has very weak or absent capabilities of self-reflection, metacognition, and self-awareness (Edelman et al., 2011). It is largely ignorant of the dominating influence of the unconscious mind. The cognitive self is similar to Edelman's higher-order consciousness in that it is conscious of being conscious. Although most of the cognitive self exists in our dominant subconscious and unconscious, when we enter into higher levels of consciousness, this self begins to enter into awareness and influence. At any moment in time, our unified sense of self and being is a combination and interaction of these two selves which is reflected biologically in tones of the ANS.

We propose that when the emotional self is dominant, the sympathetic nervous system is dominant, showing the emotional self's relationship to the "flight or fight" response. This self is thus important for acting against distress and times where survival is endangered. Because this self is primed to act in the now and act on emotional impulse, it is most suitable to act selfishly and violently if needed. Thus, extended states of distress leading to extended dominance of the emotional self can lead to psychiatric disorders in which self-awareness and emotional control are lacking such as anxiety, depression, anger, and other mood disorders. When the cognitive self is dominant, the parasympathetic state is dominant. This state is most active at rest and when stress is not present, allowing one to reflect, contemplate, and daydream without the threat of danger. 
The cognitive self is much more altruistic and compassionate, putting effort into developing long-term survival strategies such as fostering community instead of deflecting immediate danger. Therefore, this self does not need to act on evolutionarily crafted impulse and is free to explore the vast vaults and potential of one's psyche.

These selves have neuropsychological coordinates and interaction dynamics. The emotional self is most familiar to common views on the self, having neural correlates primarily in the DMN and limbic/brainstem areas. The personal experience of the self is a generation of these selves which can be considered an informed hallucination in that it is often grounded in opinion and belief, not necessarily reality. For instance, one may believe they are much smarter than they are or even possess body parts that they do not (Kammers et al., 2009). Primarily, the experience and perspective of the self is a construct maintained to allow for effective confluence with one's social and ecological environment (Baumeister \& Bushman, 2010).

The harmony between the two selves is necessary for a stable, healthy, and happy psychological state. This interaction is evident in self-talk, which can consist of many forms such as thoughts and facial expressions. Through self-talk, one can have a means of coordination between the two selves. In this way, the cognitive mind can be geared to function in the fashion that the emotional mind desires. When poor coordination between the two selves manifests, one may have trouble staying on task and committing ones entire effort into a goal. Although the cognitive mind holds great power over how we see the world and our relationship to it, its boundaries with the external world as well as its ego are blurry. Therefore, its conscious expression is less relatable to personal interaction with the environment.

\section{The Spectrum of Self-Relationship}

We have suggested that in the cognitive state of mind, one has an overall greater amount of consciousness and awareness of one's psyche. With the much greater dominance in unconscious brain activity compared to conscious activity (Eagleman, 2011), surely it is not evolutionarily desirable or physically possible for one to become consciously aware of the majority of such activity. We assert that just becoming aware of every module of this activity would not contribute to one's psychological well-being. Imagine at every moment being aware of every insignificant memory you have stored or every fear you possess. People with hyperthymesia can remember almost every little detail of anything that has happened to them over their lives; however, they often describe the experience as miserable as a constant, irrepressible flow of memories interrupt things they enjoy in their daily lives (Yamashita, 2013).

Although consciously gaining control of unconscious processes certainly has its benefits, we assert the greater importance of a healthy relationship between the two selves. We believe this relationship lies on a spectrum, which may be reflected physiologically in ANS activity. Those with the healthiest self-relationship 
may exist in a state of "spiritual euphoria" with sensations of expansion and unification of mind (Meares, 2012). On the opposite end of the spectrum lies a painfully incoherent state, which can be demonstrated physiologically. This spectrum end results from or results in borderline personality disorder (BPD) (Meares, 2012). People with BPD experience intense mood swings and have a distorted uncertainty about their self-image and their role in the world. They suffer from relationship instability, self-harming behavior, chronic feelings of emptiness, and a lack of trust. This condition may develop due to a lack of proper development of one's sense of self (Meares, 2012).

We have proposed a spectrum of self-relationship based on previously proposed spectrum of the emotional self (Figure 1) (Jerath, 2010). This emotional spectrum is a direct reflection of the level of health in our own self-relationship. Someone with a very healthy self-relationship will most often find themselves in a joyful, tranquil state of mind reflected physiologically in a parasympathetic dominated ANS. Someone with BPD or similar state will be controlled by anxiety, anger, fear, and pessimism. This state is associated with a sympathetic dominated ANS. It is clear that when stress dominates our lives, predictable physiological reactions occur. We have proposed a clear correlation between the upper end of the spectrum with lucid thinking and the lower state with clouded thinking.

In the higher end of the spectrum of the emotional self, one may feel that their experience of the world is not a direct experience of the external, but they may identify themselves with the entire experience as it is all generated by the unconscious. At this end, higher executive functions are more active such as metacognition, self-control, and self-awareness. Due to the lack of inner impulses and intrusive thoughts and emotions, one is more at peace and tranquil. Thus, behavior will be significantly different if one is in the lower state versus the higher state. In the lower state, one will lack self-control and awareness thus often acting on selfish and antisocial impulse evolutionarily designed to keep one alive in "fight or flight" moments. One can become unnaturally stuck in this lower state leading to a prolonged disconnection from the higher self. Thus, one always exists on a spectrum of higher/lower self dominance.

Although there is some criticism (Billman, 2013), several studies have shown how heart rate patterns indicate tones of dominance in the ANS. Measurement of heart rate variability (HRV) is a non-invasive technique and is used to investigate functioning of the ANS, especially the balance between the sympathetic and parasympathetic systems (von Borell et al., 2007), and can also be considered a general indicator of stress and health (Mazurak et al., 2012). Therefore, we propose this biometric can be most easily used to develop an approximation of one's position on the spectrum of self-relationship health (Figure 1). The chronic stress experienced by many due to modern lifestyles has been shown to be reducible through meditation techniques (Orme-Johnson \& Barnes, 2014). We propose that the most effective way to improve self-relationship is to practice meditative breathing exercises and other mind-body techniques, such as 


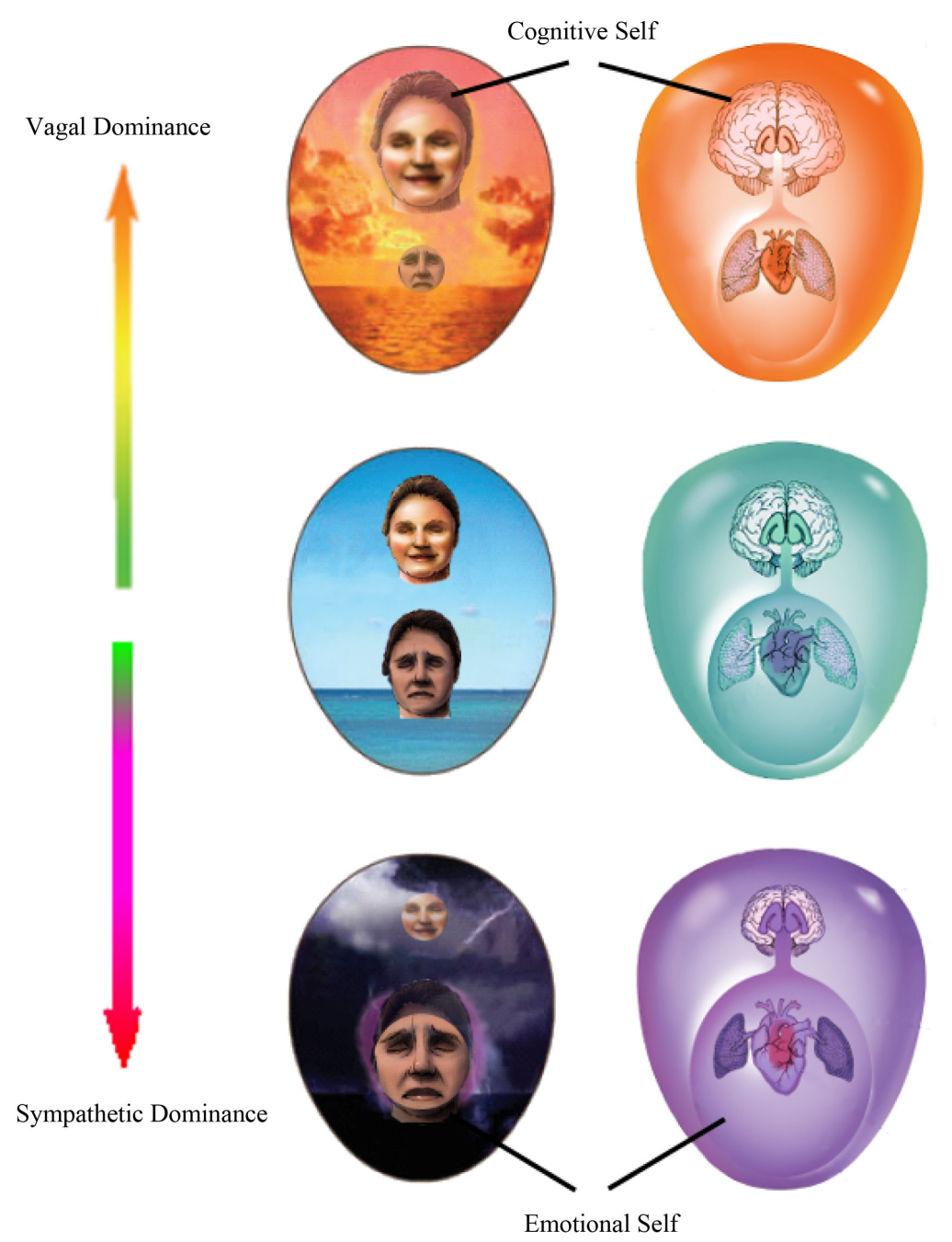

Figure 1. Spectrum of the emotional self: In this diagram, various spheres of cognitive and bodily modules provide an overall glimpse of the current state of the mind-body system. This diagram illustrates a spectrum of self-relationship health which we have correlated with the states of the autonomic nervous system. The entire egg-shaped complex represents the mind-body complex. The upper sphere in this complex represents the cognitive module. This cognitive sphere indicates the coherency and level of higher cognitive activity present in the mind. As indicated in the diagram, a person in the tranquil parasympathetic state will have larger cognitive sphere and therefore will have clearer, more rational and more compassionate thinking as well as more control over their thought process. The lower spheres are spheres of the body-focused emotional self. In the often anxiety ridden sympathetic state, The large visceral sphere in the sympathetic state indicates the increased focus on instinctual tendencies, which are non-intellectual and serve immediate selfish demands related to self-survival. The state of the ANS is thus not only a predictor of physical and mental states, but is a predictor of the state of self-health.

Transcendental Meditation (Travis \& Shear, 2010). Mind-body techniques follow the theory of embodied cognition in which the mind not only affects the body, but the body affects the mind via dynamic interactions (Wilson \& Foglia, 2017). Thus, we can modulate self-cognition through voluntarily modulating certain bodily processes such as breathing. Through meditation practice, one 
may be able to develop their cognitive self and become aware that the emotional self is itself a virtual construct. The centeredness in a virtual 3D spatial matrix of consciousness can thus be identified only a virtual locus of self and one can identify their cognitive self in more a "selfless" manner.

\section{Meditative Experiences}

We have explained how certain DMN modules and networks are the main neural correlate of the emotional self; therefore, practices that alter the experience of the self should alter the neural correlate. Although different modules of the DMN serve different functions to the self, meditation has been shown to inhibit activity in forms of meditation that involve greater concentration, cognitive control and mindfulness (Brewer et al., 2011) and reduce functional connectivity among the DMN (Berkovich-Ohana \& Glicksohn, 2014) as a whole. The frontal subsystem of the DMN however shows increased functional synchrony (Fingelkurts et al., 2016). This frontal subsystem is responsible for the experience of being a self at the center of an externalized, spatial, multisensory reality (Revonsuo, 2006; Trehub, 2007), and its increased activity and connectivity in meditative practitioners is associated with increased empathy and joy (Fingelkurts et al., 2016). The nature of a transcendent experience in which the centeredness in a 3D virtual space becomes altered has been studied via neural observation of practiced meditators in relation to the frontal DMN subsystem (Fingelkurts et al., 2016). While some say this center is never lost (Nash et al., 2013) and some say it is lost with meditation, meditation may bring one to not identify oneself with the center, but to identify the entire externalized perceptual reality with oneself. As described, this supports our hypothesis in that this externalized but internally generated perceptual reality is a product of the unconscious mind.

In line with this hypothesis, many advanced meditators report an "absolute unitary being", a loss of bodily sensations, and/or a loss of self-boundaries (Newberg et al., 2001). These experiences of diminished embodiment and localization of the physical self have been correlated with diminished integrity of the posterior DMN subnets (Fingelkurts et al., 2016). Some meditators report a complete loss of bodily ownership where the body is no longer associated with their sense of self, instead they experience the self purely with the phenomenon of experience (Dor-Ziderman et al., 2013). In this state, we propose the cognitive self is most active. Lack of functional integration of these posterior subnets due to meditative practice has also been associated with experiences of a peaceful state of mind, expanded consciousness, and the feeling that "all is one" (Hinterberger et al., 2011; Fingelkurts et al., 2016). In addition, dysfunctional posterior DMN subnets in non-meditators have been associated with out of body experiences (Ionta et al., 2011).

\section{Conclusion}

Understanding of the self has been a subject for writers, philosophers, research 
scientists and others for centuries. It is highly complex and current descriptions lack critical elements such as neuro-scientific basis and the dynamic ever-changing behavior of a person. Many times a person does not know why he/she behaved the way they do. This leads to preventable arguments, breakups and crimes. They also may suffer from mood swings and emotional roller coasters that lead them into state anxiety, depression, anger, and even suicide. When we are shifted to a sympathetic state, our emotional individual and social behavior is supported by an agitated state of self-relationship. This agitated or abnormal state may generate an abnormal or destructive behavioral response due to a lack of regulation of the impulsive emotional self by the cognitive self leading to fear, panic attacks, and depression.

Based on self-assessments and biometric assessments such as pulse, heart rate, and blood pressure monitoring one can find their position on the spectrum of self-relationship. If it is shifted towards sympathetic dominance, they can make appropriate corrective actions such as positive thinking, biofeedback, meditation, pranayama, exercise, or mind-body techniques that change ones autonomic state to a more parasympathetic dominance, supporting positive thoughts and clear, calm thinking. If this hypothesis is shown to be correct, better psychiatric therapies can be developed. Patients with anxiety and various emotional problems may understand their inner chatter and they may be able to make better decisions by identifying the poor cognitive and behavioral results of an overactive emotional self. Negative thoughts may be decreased by identifying them with the emotional self gone awry, overall improving well-being and productive thinking. Future applications may include better emotional and cognitive state recognition by biometric technologies.

\section{Author Contributions}

Theory developed by RJ with some writing with majority of the manuscript written by CB.

\section{Funding}

All funding provided by the Charitable Medical Healthcare Foundation.

\section{Conflicts of Interest}

The authors declare no conflict of interest.

\section{References}

Andrews-Hanna, J. R., Smallwood, J., \& Spreng, R. N. (2014). The Default Network and Self-Generated Thought: Component Processes, Dynamic Control, and Clinical Relevance. Annals of the New York Academy of Sciences, 1316, 29-52.

https://doi.org/10.1111/nyas.12360

Au-Ma, K., Au-Lippelt, D. P., \& Au-Hommel, B. (2017). Creating Virtual-Hand and Virtual-Face Illusions to Investigate Self-Representation. Journal of Visualized Experi- 
ments, 121, e54784. https://doi.org/10.3791/54784

Barton, D. A., Dawood, T., Lambert, E. A., Esler, M. D., Haikerwal, D., Brenchley, C., Socratous, F., Kaye, D. M., Schlaich, M. P., Hickie, I., \& Lambert, G. W. (2007). Sympathetic Activity in Major Depressive Disorder: Identifying Those at Increased Cardiac Risk? Journal of Hypertension, 25, 2117-2124.

https://doi.org/10.1097/HJH.0b013e32829baae7

Baumeister, R., \& Bushman, B. (2010). The Self. In Social Psychology and Human Nature (pp. 57-96). Belmont, CA: Wadsworth Publishing.

Berkovich-Ohana, A., \& Glicksohn, J. (2014). The Consciousness State Space (CSS)—A Unifying Model for Consciousness and Self. Frontiers in Psychology, 5, 341.

https://doi.org/10.3389/fpsyg.2014.00341

Billman, G. (2013). The LF/HF Ratio Does Not Accurately Measure Cardiac Sympathovagal Balance. Frontiers in Physiology, 4, 26.

https://doi.org/10.3389/fphys.2013.00026

Blavatsky, H. P. (1889). The Key to Theosophy. Scotts Valley, CA: CreateSpace.

Botvinick, M., \& Cohen, J. (1998). Rubber Hands "Feel” Touch That Eyes See. Nature, 391, 756. https://doi.org/10.1038/35784

Brewer, J. A., Worhunsky, P. D., Gray, J. R., Tang, Y. Y., Weber, J., \& Kober, H. (2011). Meditation Experience Is Associated with Differences in Default Mode Network Activity and Connectivity. Proceedings of the National Academy of Sciences of the United States of America, 108, 20254-20259. https://doi.org/10.1073/pnas.1112029108

Brodal, P. (2004). The Central Nervous System: Structure and Function. Oxford: Oxford University Press.

Converse, R. L., Jacobsen, T. N., Toto, R. D., Jost, C. M. T., Cosentino, F., Fouad-Tarazi, F., \& Victor, R. G. (1992). Sympathetic Overactivity in Patients with Chronic Renal Failure. New England Journal of Medicine, 327, 1912-1918.

https://doi.org/10.1056/NEJM199212313272704

Curtis, B. M., \& O'keefe Jr., J. H. (2002). Autonomic Tone as a Cardiovascular Risk Factor: The Dangers of Chronic Fight or Flight. Mayo Clinic Proceedings, 77, 45-54. https://doi.org/10.4065/77.1.45

De Waal, F. B. M. (2007). Putting the Altruism Back into Altruism: The Evolution of Empathy. Annual Review of Psychology, 59, 279-300. https://doi.org/10.1146/annurev.psych.59.103006.093625

Demiralp, T., Bayraktaroglu, Z., Lenz, D., Junge, S., Busch, N. A., \& Herrmann, C. S. (2006). The Interaction of Theta and Gamma Oscillations in Human Cognition. International Journal of Psychophysiology, 61, 309.

Denton, D. (2006). The Primordial Emotions: The Dawning of Consciousness. Oxford: Oxford University Press. https://doi.org/10.1093/acprof:oso/9780199203147.001.0001

Dequattro, V., \& Hamad, R. (1985). The Role of Stress and the Sympathetic Nervous System in Hypertension and Ischemic Heart Disease: Advantages of Therapy with Beta-Receptor Blockers. Clinical and Experimental Hypertension, 7, 907-932. https://doi.org/10.3109/10641968509077238

Donaldson, C., Lam, D., \& Mathews, A. (2007). Rumination and Attention in Major Depression. Behaviour Research and Therapy, 45, 2664-2678. https://doi.org/10.1016/j.brat.2007.07.002

Dor-Ziderman, Y., Berkovich-Ohana, A., Glicksohn, J., \& Goldstein, A. (2013). Mindfulness-Induced Selflessness: A MEG Neurophenomenological Study. Frontiers in Human Neuroscience, 7, 582. https://doi.org/10.3389/fnhum.2013.00582 
Eagleman, D. (2011). Incognito: The Secret Lives of the Brain. New York: Pantheon.

Edelman, G. M. (2003). Naturalizing Consciousness: A Theoretical Framework. Proceedings of the National Academy of Sciences, 100, 5520-5524. https://doi.org/10.1073/pnas.0931349100

Edelman, G. M., Gally, J. A., \& Baars, B. J. (2011). Biology of Consciousness. Frontiers in Psychology, 2, 4. https://doi.org/10.3389/fpsyg.2011.00004

Eisenberger, N. I., Lieberman, M. D., \& Satpute, A. B. (2005). Personality from a Controlled Processing Perspective: An fMRI Study of Neuroticism, Extraversion, and Self-Consciousness. Cognitive, Affective, \& Behavioral Neuroscience, 5, 169-181. https://doi.org/10.3758/CABN.5.2.169

Farb, N. A. S., Segal, Z. V., Mayberg, H., Bean, J., Mckeon, D., Fatima, Z., \& Anderson, A. K. (2007). Attending to the Present: Mindfulness Meditation Reveals Distinct Neural Modes of Self-Reference. Social Cognitive and Affective Neuroscience, 2, 313-322. https://doi.org/10.1093/scan/nsm030

Fernyhough, C., \& Fradley, E. (2005). Private Speech on an Executive Task: Relations with Task Difficulty and Task Performance. Cognitive Development, 20, 103-120. https://doi.org/10.1016/j.cogdev.2004.11.002

Fingelkurts, A. A., Fingelkurts, A. A., \& Kallio-Tamminen (2016). Long-Term Meditation Training Induced Changes in the Operational Synchrony of Default Mode Network Modules during a Resting State. Cognitive Processing, 17, 27-37. https://doi.org/10.1007/s10339-015-0743-4

Fingelkurts, A. A., Fingelkurts, A. A., \& Neves, C. F. H. (2010). Natural World Physical, Brain Operational, and Mind Phenomenal Space-Time. Physics of Life Reviews, 7, 195-249. https://doi.org/10.1016/j.plrev.2010.04.001

Fingelkurts, A. A., Fingelkurts, A. A., Bagnato, S., Boccagni, C., \& Galardi, G. (2011). Life or Death: Prognostic Value of a Resting EEG with Regards to Survival in Patients in Vegetative and Minimally Conscious States. PLoS ONE, 6, e25967. https://doi.org/10.1371/journal.pone.0025967

Fisher, J. P., Young, C. N., \& Fadel, P. J. (2009). Central Sympathetic Overactivity: Maladies and Mechanisms. Autonomic Neuroscience: Basic \& Clinical, 148, 5-15. https://doi.org/10.1016/j.autneu.2009.02.003

Geurts, B. (2018). Making Sense of Self Talk. Review of Philosophy and Psychology, 9, 271-285. https://doi.org/10.1007/s13164-017-0375-y

Grassi, G., Seravalle, G., Quarti-Trevano, F., Scopelliti, F., Dell'oro, R., Bolla, G., \& Mancia, G. (2007). Excessive Sympathetic Activation in Heart Failure with Obesity and Metabolic Syndrome. Hypertension, 49, 535-541. https://doi.org/10.1161/01.HYP.0000255983.32896.b9

Greenwood, J. P., Scott, E. M., Walker, J. J., Stoker, J. B., \& Mary, D. A. S. G. (2003). The Magnitude of Sympathetic Hyperactivity in Pregnancy-Induced Hypertension and Preeclampsia. American Journal of Hypertension, 16, 194-199.

https://doi.org/10.1016/S0895-7061(02)03256-9

Hardy, J. (2006). Speaking Clearly: A Critical Review of the Self-Talk Literature. Psychology of Sport and Exercise, 7, 81-97.

https://doi.org/10.1016/j.psychsport.2005.04.002

Hatzigeorgiadis, A., \& Galanis, E. (2017). Self-Talk Effectiveness and Attention. Current Opinion in Psychology, 16, 138-142. https://doi.org/10.1016/j.copsyc.2017.05.014

Heatherton, T. F. (2010). Neuroscience of Self and Self-Regulation. Annual Review of Psychology, 62, 363-390. https://doi.org/10.1146/annurev.psych.121208.131616 
Heavey, C. L., \& Hurlburt, R. T. (2008). The Phenomena of Inner Experience. Consciousness and Cognition, 17, 798-810.

https://doi.org/10.1016/j.concog.2007.12.006

Hinterberger, T., Kamei, T., \& Walach, H. (2011). Psychophysiological Classification and Staging of Mental States during Meditative Practice. Biomedical Engineering, 56, 341-350. https://doi.org/10.1515/BMT.2011.021

Holcombe, A. D., \& Holcombe, S. (2005). Biblically-Derived Concept of Mankind's Higher-Self-Lower Self Nature. Journal of Religion \& Psychical Research, 28, 20-25.

Hommel, B. (2009). Action Control According to TEC (Theory of Event Coding). Psychological Research PRPF, 73, 512-526. https://doi.org/10.1007/s00426-009-0234-2

Huggett Robert, J., Scott Eleanor, M., Gilbey Stephen, G., Stoker John, B., Mackintosh Alan, F., \& Mary David, A. S. G. (2003). Impact of Type 2 Diabetes Mellitus on Sympathetic Neural Mechanisms in Hypertension. Circulation, 108, 3097-3101. https://doi.org/10.1161/01.CIR.0000103123.66264.FE

Ionta, S., Gassert, R., \& Blanke, O. (2011). Multi-Sensory and Sensorimotor Foundation of Bodily Self-Consciousness-An Interdisciplinary Approach. Frontiers in Psychology, 2, 383. https://doi.org/10.3389/fpsyg.2011.00383

James, W. (1890). Principles of Psychology. New York: Henry-Holt and Co. https://doi.org/10.1037/10538-000

Jensvold, M. L. (2014). Experimental Conversations: Sign Language Studies with Chimpanzees. In The Evolution of Social Communication in Primates: A Multidisciplinary Approach (pp. 63-82). Gontier: Springer. https://doi.org/10.1007/978-3-319-02669-5 4

Jerath, R. (2010). Pranayama: Converting Stress \& Anxiety into Inner Joy. Bloomington, IN: AuthorHouse.

Jerath, R., \& Beveridge, C. (2019). Multimodal Integration and Phenomenal Spatiotemporal Binding: A Perspective from the Default Space Theory. Frontiers in Integrative Neuroscience, 13, 2. https://doi.org/10.3389/fnint.2019.00002

Jerath, R., Cearley, S. M., Barnes, V. A., \& Jensen, M. (2016). Meditation Experiences, Self, and Boundaries of Consciousness. International Journal of Complementary \& Alternative Medicine, 4, Article ID: 00105. https://doi.org/10.15406/ijcam.2016.04.00105

Jerath, R., Crawford, M. W., \& Barnes, V. A. (2015). A Unified 3D Default Space Consciousness Model Combining Neurological and Physiological Processes That Underlie Conscious Experience. Frontiers in Psychology, 6, Article 1204. https://doi.org/10.3389/fpsyg.2015.01204

Jerath, R., Edry, J. W., Barnes, V. A., \& Jerath, V. (2006). Physiology of Long Pranayamic Breathing: Neural Respiratory Elements May Provide a Mechanism That Explains How Slow Deep Breathing Shifts the Autonomic Nervous System. Medical Hypotheses, 67, 566-571. https://doi.org/10.1016/j.mehy.2006.02.042

Jowett, B. (1871). Dialogues of Plato, Translated into English with Analyses and Introduction. Cambridge: Cambridge University Press.

Kales, A., Caldwell, A. B., Preston, T. A., Healey, S., \& Kales, J. D. (1976). Personality Patterns in Insomnia: Theoretical Implications. JAMA Psychiatry, 33, 1128-1134. https://doi.org/10.1001/archpsyc.1976.01770090118013

Kammers, M. P., De Vignemont, F., Verhagen, L., \& Dijkerman, H. C. (2009). The Rubber Hand Illusion in Action. Neuropsychologia, 47, 204-211.

https://doi.org/10.1016/j.neuropsychologia.2008.07.028 
Kreibig, S. D. (2010). Autonomic Nervous System Activity in Emotion: A Review. Biological Psychology, 84, 394-421. https://doi.org/10.1016/j.biopsycho.2010.03.010

Leary, M. R. (2004). The Curse of the Self: Self-Awareness, Egotism, and the Quality of Human Life. New York: Oxford Univ. Press. https://doi.org/10.1093/acprof:oso/9780195172423.001.0001

Levenson, R. W. (2014). The Autonomic Nervous System and Emotion. Emotion Review, 6, 100-112. https://doi.org/10.1177/1754073913512003

Macrae, C. N., Moran, J. M., Heatherton, T. F., Banfield, J. F., \& Kelley, W. M. (2004). Medial Prefrontal Activity Predicts Memory for Self. Cerebral Cortex, 14, 647-654. https://doi.org/10.1093/cercor/bhh025

Malpas, S. C. (2010). Sympathetic Nervous System Overactivity and Its Role in the Development of Cardiovascular Disease. Physiological Reviews, 90, 513-557. https://doi.org/10.1152/physrev.00007.2009

Mazurak, N., Seredyuk, N., Sauer, H., Teufel, M., \& Enck, P. (2012). Heart Rate Variability in the Irritable Bowel Syndrome: A Review of the Literature. Neurogastroenterology \& Motility, 24, 206-216. https://doi.org/10.1111/j.1365-2982.2011.01866.x

Meares, R. (2012). The Sense of the Spirit as a Form of Conversation. Asian Journal of Psychiatry, 5, 190-192. https://doi.org/10.1016/j.ajp.2012.05.002

Moran, J. M., Kelley, W. M., \& Heatherton, T. F. (2013). Self-Knowledge. In K. N. Ochsner, \& S. Kosslyn (Eds.), Oxford Handbook of Cognitive Neuroscience (pp. 135-147). New York: Oxford Univ. Press.

Moran, J. M., Macrae, C. N., Heatherton, T. F., Wyland, C. L., \& Kelley, W. M. (2006). Neuroanatomical Evidence for Distinct Cognitive and Affective Components of Self. Journal of Cognitive Neuroscience, 18, 1586-1594. https://doi.org/10.1162/jocn.2006.18.9.1586

Moser, J. S., Dougherty, A., Mattson, W. I., Katz, B., Moran, T. P., Guevarra, D., Shablack, H., Ayduk, O., Jonides, J., Berman, M. G., \& Kross, E. (2017). Third-Person Self-Talk Facilitates Emotion Regulation without Engaging Cognitive Control: Converging Evidence from ERP and fMRI. Scientific Reports, 7, Article No. 4519. https://doi.org/10.1038/s41598-017-04047-3

Musholt, K. (2013). A Philosophical Perspective on the Relation between Cortical Midline Structures and the Self. Frontiers in Human Neuroscience, 7, 536. https://doi.org/10.3389/fnhum.2013.00536

Nash, J. D., Newberg, A., \& Awasthi, B. (2013). Toward a Unifying Taxonomy and Definition for Meditation. Frontiers in Psychology, 4, 806. https://doi.org/10.3389/fpsyg.2013.00806

Nataraja, S. (2008). The Blissful Brain: Neuroscience and Proof of the Power of Meditation. London, United Kingdom: Gaia Books.

Nelson, D. L., \& Simmons, B. L. (2004). Eustress: An Elusive Construct an Engaging Pursuit. Oxford: Elsevier Jai.

Nesse, R. M., Bhatnagar, S., \& Ellis, B. J. (2016). Evolutionary Origins and Functions of the Stress Response System. In Stress: Concepts, Cognition, Emotion, and Behavior (pp. 95-101). Cambridge, MA: Academic Press. https://doi.org/10.1016/B978-0-12-800951-2.00011-X

Newberg, A. B., \& D’aquili, E. G. (1999). Mystical Mind. Minneapolis, MN: Fortress Press.

Newberg, A., Alavi, A., Baime, M., Pourdehnad, M., Santanna, J., \& D’aquili, E. (2001). 
The Measurement of Regional Cerebral Blood Flow during the Complex Cognitive Task of Meditation: A Preliminary SPECT Study. Psychiatry Research, 106, 113-122. https://doi.org/10.1016/S0925-4927(01)00074-9

Oizumi, M., Albantakis, L., \& Tononi, G. (2014). From the Phenomenology to the Mechanisms of Consciousness: Integrated Information Theory 3.0. PLOS Computational Biology, 10, e1003588. https://doi.org/10.1371/journal.pcbi.1003588

Orme-Johnson, D. W., \& Barnes, V. A. (2014). Effects of the Transcendental Meditation Technique on Trait Anxiety: A Meta-Analysis of Randomized Controlled Trials. Journal of Alternative and Complementary Medicine, 20, 330-341.

https://doi.org/10.1089/acm.2013.0204

Praet, D. V. (2012). Unconscious Branding: How Neuroscience Can Empower (and Inspire) Marketing. New York, NY: St. Martin's Press.

Revonsuo, A. (2006). Inner Presence: Consciousness as a Biological Phenomenon. Cambridge, MA: MIT Press.

Sedikides, C., \& Spencer, S. J. (2007). The Self (Frontiers of Social Psychology). New York: Psychology Press.

Theodorakis, Y., Chroni, S., Laparidis, K., Bebetsos, V., \& Douma, I. (2001). Self-Talk in a Basketball-Shooting Task. Perceptual and Motor Skills, 92, 309-315. https://doi.org/10.2466/pms.2001.92.1.309

Travis, F., \& Shear, J. (2010). Focused Attention, Open Monitoring and Automatic Self-Transcending: Categories to Organize Meditations from Vedic, Buddhist and Chinese Traditions. Consciousness and Cognition, 19, 1110-1118.

https://doi.org/10.1016/j.concog.2010.01.007

Trehub, A. (2007). Space, Self, and the Theater of Consciousness. Consciousness and Cognition, 16, 310-330. https://doi.org/10.1016/j.concog.2006.06.004

Tsakiris, M., Hesse, M. D., Boy, C., Haggard, P., \& Fink, G. R. (2007). Neural Signatures of Body Ownership: A Sensory Network for Bodily Self-Consciousness. Cereb Cortex, 17, 2235-2244. https://doi.org/10.1093/cercor/bhl131

Vicente, A., \& Martinez Manrique, F. (2011). Inner Speech: Nature and Functions. Philosophy Compass, 6, 209-219. https://doi.org/10.1111/j.1747-9991.2010.00369.x

Von Borell, E., Langbein, J., Després, G., Hansen, S., Leterrier, C., Marchant-Forde, J., Marchant-Forde, R., Minero, M., Mohr, E., Prunier, A., Valance, D., \& Veissier, I. (2007). Heart Rate Variability as a Measure of Autonomic Regulation of Cardiac Activity for Assessing Stress and Welfare in Farm Animals-A Review. Physiology \& Behavior, 92, 293-316. https://doi.org/10.1016/j.physbeh.2007.01.007

Westen, D. (1999). The Scientific Status of Unconscious Processes: Is Freud Really Dead? Journal of the American Psychoanalytic Association, 47, 1061-1106. https://doi.org/10.1177/000306519904700404

Wilson, R. A., \& Foglia, L. (2017). Embodied Cognition. In The Stanford Encyclopedia of Philosophy (p. 1). Stanford, CA: Metaphysics Research Lab, Stanford University.

Yamashita, M. (2013). Electric Axon Guidance in Embryonic Retina: Galvanotropism Revisited. Biochemical and Biophysical Research Communications, 431, 280-283. https://doi.org/10.1016/j.bbrc.2012.12.115 